\title{
Development and Validation of HPTLC Method for Quantification of Biomarker $\beta$-Sitosterol in the Leaves of Achyranthes aspera Linn.
}

\author{
APARNA SARAF* and ARUNA SAMANT \\ The Institute of Science, 15, Madame Cama Road, Fort, Mumbai-400 032, India \\ draparnasaraf@yahoo.co.in
}

Received 25 September 2015 / Accepted 5 October 2015

\begin{abstract}
A simple and sensitive high-performance thin-layer chromatographic (HPTLC) method was developed for the evaluation of biomarker $\beta$ - sitosterol in the leaves of Achyranthes aspera Linn. belonging to family Amaranthaceae. Chromatography was performed on silica gel 60 F254 precoated HPTLC plates with solvents Toluene: Ethyl acetate: Glacial acetic acid 14.5: 4.5: 1.0 $(\mathrm{v} / \mathrm{v} / \mathrm{v})$ as the mobile phase. After development, the HPTLC plate was derivatized with anisaldehyde sulphuric acid, scanned, and quantified at $540 \mathrm{~nm}$. The system was found to give compact spot for $\beta$ sitosterol at $\mathrm{RF}=0.61 \pm 0.02$. The mean of $\% \mathrm{RSD}$ value $(n=6)$ in Intra-day and Inter-day precisions studies for $\beta$ - sitosterol were found to be $0.04 \%$ and $0.09 \%$, respectively. The concentration of $\beta$ sitosterol in leaf of the plant is found to be $0.699 \mathrm{ng} / \mu \mathrm{g}$. The statistical analysis proved that the developed method is suitable and specific. The developed method can be used as an important tool to assure the therapeutic dose of active ingredients in herbal formulations as well as for standardization and quality control of bulk drugs and in-process formulations.
\end{abstract}

Keywords: Achyranthes aspera Linn., $\beta$ - sitosterol, HPTLC, Quantification, Validation

\section{Introduction}

The natural products predominantly found in plants can be used as marker compounds for establishing authenticity of that plant or plant parts. A properly developed and validated method of quantification can be used for phytochemical profiling and estimation of the standard compounds.

Achyranthes aspera Linn. (Fam. Amranthaceae) is an erect or procumbent, annual or perennial herb, 1-2 $\mathrm{m}$ in height, often with a woody base, commonly found as a weed of waysides, on roadsides ${ }^{1-3}$. Although it has many medicinal properties, it is particularly used spermicidal $^{4}$, antipyretic ${ }^{5}$ and as a cardiovascular agent ${ }^{6}$. It is used by traditional healers for the treatment of fever, dysentery and diabetes ${ }^{7}$. Leaf decoction for cardiovascular toxicity has been reported ${ }^{8}$ and the ethanol crude extract showed high larvicidal activity on the tick larvae against Boophilis microplus ${ }^{9}$. The ethanolic extract of the leaves and stem of the plant 
inhibited the growth of Bacillus subtilis and Staphylococcus aureus bacterial strains ${ }^{10}$. Roots are used as astringents to wounds, in abdominal tumor and stomach pain ${ }^{11}$. Leaf extracts were reported to posses thyroid stimulating, antiperoxidative and antifungal activity properties ${ }^{12-13}$.

$\beta$-Sitosterol is found in leaves of Achyranthes aspera Linn. and can be used as biomarker to establish the authenticity of the plant. $\beta$-Sitosterol is a phytosterols possessing broad range of biological activities. $\beta$-Sitosterol is a main phytosterol, found in numerous plants including rice, wheat, corn, nut, peanut etc., $\beta$-sitosterol has recorded an amazing health benefits as an hepatoprotective ${ }^{14}$, antioxidant and antipyretic ${ }^{15}$, inflammatory disorders and immunomodulatory ${ }^{16}$, antiinflammatory ${ }^{17}$ and rheumatoid arthritis ${ }^{18}$ $\beta$-sitosterol is reported in Achyranthes aspera Linn. and present study is aimed at method development, validation and quantification of $\beta$-sitosterol by following ICH guidelines ${ }^{19}$.

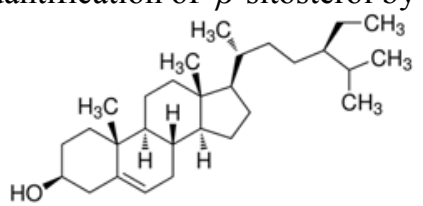

Figure 1. $\beta$-Sitosterol

Synonyms: Cupreol, Cinchol, $\alpha$-phytosterol, Rhamnol, Quebrachol

Molecular formula $: \mathrm{C}_{29} \mathrm{H}_{50} \mathrm{O}$

Molecular weight : 414.71

Chemical class/group: Terpenes (Subclass: Triterpenes)

\section{Experimental}

Whole plants of Achyranthes aspera Linn. were collected in the month of AugustSeptember 2013 from natural habitats in Vasai region of Thane district. The plants were authenticated at Blatter's herbarium; St. Xavier's College, Mumbai and the specimens voucher were deposited in the St. Xavier's College Herbarium for further reference. The accession number for Achyranthes aspera L. is 62490.

\section{Apparatus and Reagents}

Instrument

Camag Linomat V sample applicator, Camag Twin trough glass chamber and Camag TLC Scanner IV equipped with Cats 1.4.6 version software.

\section{Reagents}

Toluene, ethyl acetate, glacial acetic acids, methanol and acetone were of analytical reagent grade with $99.8 \%$ purity. They were obtained from S. D. Fine chemicals.

\section{Standards}

Standard $\beta$-sitosterol was procured from Sigma Aldrich.

\section{Glassware}

Standard volumetric flasks and pipettes of class a grade were used for determination.

\section{Preparation of Standard Stock Solution}

Preparation of stock (A) solution of $\beta$-sitosterol $(1 \mu \mathrm{g} / \mu \mathrm{L})$

Stock (A) solutions of $\beta$-sitosterol $(1 \mu \mathrm{g} / \mu \mathrm{L})$ was prepared in methanol. $10.0 \mathrm{mg}$ of standard $\beta$-sitosterol was accurately weighed and transferred to a $10.0 \mathrm{~mL}$ standard volumetric flask. 
The contents of the flask were initially dissolved in $5.0 \mathrm{~mL}$ of methanol, followed by sonication and then diluted up to the mark with methanol.

\section{Preparation of stock (B) solution for $\beta$-sitosterol $(0.1 \mu \mathrm{g} / \mu \mathrm{L})$}

From the standard stock (A) solution, $0.1 \mathrm{~mL}$ was transferred to a $10.0 \mathrm{~mL}$ standard volumetric flask. The contents of the flask were initially dissolved in $5.0 \mathrm{~mL}$ of methanol, followed by sonication and then diluted up to the mark with methanol. Thus a working stock solution of $\beta$-sitosterol of $0.1 \mu \mathrm{g} / \mu \mathrm{L}$ was prepared in methanol.

\section{Preparation of samples}

$\beta$-Sitosterol is freely soluble in methanol, hence methanol was used for extraction from plant powder during method development and validation for the plant. Plant extracts of the concentration $50 \mu \mathrm{g} / \mu \mathrm{L}$ were prepared. During the process, $500 \mathrm{mg}$ of leaf powder of Achyranthes aspera Linn. was extracted with $10.0 \mathrm{~mL}$ of methanol. The mixture was sonicated for $30 \mathrm{~min}$ and it was kept overnight for extraction. It was filtered through Whatmann filter paper No. 41 and filtrate obtained was subjected to HPTLC for quantification of $\beta$ - sitosterol. $10 \mu \mathrm{L}$ of the sample solution was applied along with standard solution for quantification.

\section{Method development}

Chromatogram was developed for $\beta$-sitosterol by selecting the mobile phase after trying several combinations of solvents. The best resolution was observed in the selected (Toluene: Ethyl Acetate: Glacial Acetic Acid (14.5: 4.5: 1.0) (v/v/v)) mobile phase or solvent system. The optimized saturation time was observed as $20 \mathrm{~min}$. The developed HPTLC plate was dried at $105{ }^{\circ} \mathrm{C}$, derivatized with anisaldehyde sulphuric acid reagent and again heated to identify compact bands. Densitometric analysis was performed at absorption maxima of wavelength $540 \mathrm{~nm}$ in absorbance-reflectance mode (Table 1).

Table 1. Chromatographic conditions for HPTLC studies

\begin{tabular}{ll}
\hline \multicolumn{1}{c}{ Parameters } & \multicolumn{1}{c}{ Description } \\
\hline Stationary phase & Silica gel $60 \mathrm{~F}_{254}$ pre-coated on aluminium sheet. \\
Mobile phase for $\beta$ - sitosterol & Toluene: Ethyl acetate : Glacial acetic acid \\
& 14.5: $4.5: 1.0(\mathrm{v} / \mathrm{v} / \mathrm{v})$ \\
Prewashing of the plate & Methanol and activated at $110{ }^{\circ} \mathrm{C}$ for half an hour \\
Development of the chamber & CAMAG Twin Trough Chamber \\
Chamber saturation & $20 \mathrm{~min}$ \\
Sample applicator & CAMAG LINOMAT V \\
Band length & $8 \mathrm{~mm}$ \\
Development distance & $80 \mathrm{~mm}$ \\
Derivatizing reagent & Anisaldehyde sulphuric acid \\
Drying of plate & At $110{ }^{\circ} \mathrm{C}$ for 5 min \\
Densitometric scanner & CAMAG TLC scanner IV \\
Lamp & Tungsten \\
Wavelength & $540 \mathrm{~nm}$ \\
Chromatographic evaluation & CAMAG TLC software Win cats1.4.6
\end{tabular}

\section{Method validation}

Validation of the developed method has been carried out as per the ICH guidelines for linearity, precision, accuracy, limits of detection (LOD) and quantification (LOQ), specificity and System suitability studies. 


\section{Linearity range}

For determining the linearity range of standard $\beta$-sitosterol, a series of 7 spots of different volumes ranging from $0.1 \mu \mathrm{L}-0.4 \mu \mathrm{L}$ was applied on HPTLC plate. The plate was scanned, and a curve was prepared with respect to peak area $v s$. Concentration per spot.

\section{Precision and accuracy}

Precision (inter- and intra-day) and accuracy of the assay were evaluated as per the ICH norms. Intra-day precision was performed by application of the six bands (each $5 \mu \mathrm{L}$ ) of standard $\beta$-sitosterol solutions $(0.1 \mu \mathrm{g} / \mu \mathrm{L})$ to a HPTLC plate, the densitograms and peak areas were recorded. Inter-day precision was performed by recording peak areas of $\beta$-sitosterol for each applied concentration at three quality control (QC) levels, i.e., low, medium and high of $0.20,0.25$ and $0.35 \mu \mathrm{g} / \mathrm{mL}$ on three consecutive days.

\section{$L O D$ and $L O Q$}

Sensitivity was determined by establishing the limit of detection (LOD) and limit of quantitation (LOQ). They were determined at a signal to noise ratio of $3: 1$ and 10:1 respectively as per the ICH guidelines, standard deviation (SD) of response and slope was calculated for LOD $(\mathrm{DL}=3.3 \times \mathrm{SD} / \mathrm{S})$ and $\mathrm{LOQ}(\mathrm{DL}=10 \times \mathrm{SD} / \mathrm{S})$.

\section{Specificity (Selectivity)}

In specificity studies, assay and impurity method was performed using the leaf extract, methanol, solvent system of toluene: ethyl acetate: glacial acetic acid in the volume ratio of 14.5: 4.5: $1.0(\mathrm{v} / \mathrm{v} / \mathrm{v})$ for $\beta$-sitosterol with chamber saturation of 20 minutes with filter paper Whatmann No.1 along with standard solution of $\beta$-sitosterol.

\section{System suitability}

The system suitability experiment was carried out by spotting $5 \mu \mathrm{L}$ of $\beta$-sitosterol solution separately on different HPTLC plates. These solutions were spotted six times each in the chromatographic conditions. Peak area and retention factor were studied to evaluate the suitability of the system.

\section{Quantitation of $\beta$-sitosterol}

The external standard method is generally used for quantification analysis in TLC studies as it assures accuracy and precision in quantitative analysis ${ }^{20}$. A chromatogram was developed using standard $\beta$-sitosterol with different concentration ranging from $2 \mu \mathrm{L}$ to $4 \mu \mathrm{L}$ and leaf extract with same concentration of $10 \mu \mathrm{L}$, plotted separately on HPTLC plate. A calibration curve was obtained by plotting standard peak area against concentration.

\section{Results and Discussion \\ Method development}

The developed method was found to be effective in the separation of constituents present in the leaf extract and exhibiting sharp peaks of standard $\beta$-sitosterol with the selected mobile phase when observed under wavelength of $540 \mathrm{~nm}$. Compact, symmetrical, and highresolution bands of $\beta$-sitosterol were obtained at RF $0.61 \pm 0.02$ (Figure 3). The developed method was found to be quite selective with good baseline resolution.

\section{Method validation}

Linearity of compound $\beta$-sitosterol was validated by the linear regression equation and correlation coefficient. The linear correlation coefficient $r=1$ obtained indicates a perfect 
positive correlation between the concentrations of $\beta$-sitosterol and the peak areas. The (RSD) of the peak areas for all concentration of $\beta$-sitosterol is always much less than $2 \%$ which indicates more reliability of the results (Figure 2 ).

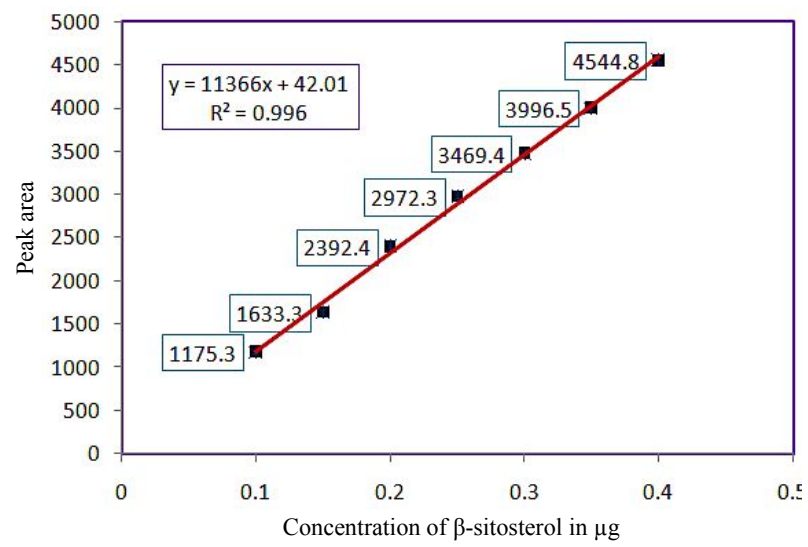

Figure 2. Linear Dynamic Range of $\beta$-sitosterol

Intra-day and inter-day precision and accuracy of the assay for $\beta$-sitosterol demonstrated good precision of the proposed method. The mean of $\%$ RSD value $(n=6)$ in intra-day and inter-day precisions studies for $\beta$-sitosterol were found to be $0.04 \%$ and $0.09 \%$, respectively (Table 2 and 3).

Table 2. Intra-day precision of $\beta$-sitosterol (As per ICH guidelines)

\begin{tabular}{cccc}
\hline $\begin{array}{c}\text { Obs. } \\
\text { No. }\end{array}$ & $\begin{array}{c}\text { Concentration of } \\
\beta \text {-sitosterol }\end{array}$ & $\begin{array}{c}\text { Peak area of } \\
\beta \text {-sitosterol }\end{array}$ & $\mathrm{R}_{\mathrm{f}}$ \\
\hline 1 & $5.0 \mu \mathrm{L}$ & 3606.32 & 0.60 \\
2 & $5.0 \mu \mathrm{L}$ & 3436.48 & 0.59 \\
3 & $5.0 \mu \mathrm{L}$ & 3398.48 & 0.59 \\
4 & $5.0 \mu \mathrm{L}$ & 3417.87 & 0.59 \\
5 & $5.0 \mu \mathrm{L}$ & 3657.93 & 0.59 \\
6 & $5.0 \mu \mathrm{L}$ & 3681.99 & 0.59 \\
& Mean & 3533.18 & 0.59 \\
& SD & 129.5 & \\
& \%RSD & 0.04 & \\
\hline
\end{tabular}

Table 3. Inter-day precision of $\beta$-sitosterol (As per ICH guidelines)

\begin{tabular}{|c|c|c|c|c|c|c|c|}
\hline \multirow{2}{*}{$\begin{array}{l}\text { Obs. } \\
\text { No. }\end{array}$} & \multirow{2}{*}{$\begin{array}{c}\text { Concentration } \\
\text { of } \beta \text {-sitosterol } \\
\text { in, } \mu \mathrm{g} / \mathrm{mL}\end{array}$} & \multicolumn{3}{|c|}{ Peak Areas } & \multirow[b]{2}{*}{ Mean } & \multirow[b]{2}{*}{ S.D. } & \multirow[b]{2}{*}{$\% \mathrm{RSD}$} \\
\hline & & Day-1 & Day-2 & Day-3 & & & \\
\hline 1 & 0.20 & 2401.1 & 2397.8 & 2399.5 & 2399.5 & 1.650 & 0.0688 \\
\hline 2 & 0.25 & 2990.3 & 2986.1 & 2989.0 & 2988.5 & 2.150 & 0.0719 \\
\hline 3 & 0.35 & 3464.6 & 3459.6 & 3469.2 & 3464.5 & $\begin{array}{l}4.801 \\
\text { Mean }\end{array}$ & $\begin{array}{c}0.1386 \\
0.0931\end{array}$ \\
\hline
\end{tabular}

${ }^{*}$ Reading of peak area is a mean of 6 readings

Limit of detection (LOD) was determined at a signal to noise ratio of 3:1 and value of limit of detection for $\beta$-sitosterol was found to be $0.02 \mu \mathrm{g} / \mathrm{mL}$. Limit of quantitation (LOQ) was determined at a signal to noise ratio of 10:1 and value of limit of quantification for 
$\beta$-sitosterol was found to be $0.06 \mu \mathrm{g} / \mathrm{mL}$. This indicated the sensitivity of the instrument for the quantification of above compound. The method was found to be very specific as the densitograms shows positive response of only the leaf extract for the presence of $\beta$-sitosterol and the standard $\beta$-sitosterol solution where as completely negative response is given by the diluent methanol and the mobile phase, toluene: ethyl acetate: glacial acetic acid in the volume ratio of 14.5: 4.5: $1.0(\mathrm{v} / \mathrm{v} / \mathrm{v})$. The densitograms obtained by loading six spots of equal volume indicates the same peak area and same retention factor of 0.59 for all the six spots (Figure 3). The peak area and the $\mathrm{R}_{\mathrm{f}}$ values for the six spots of $\beta$-sitosterol are recorded. The relative standard deviation for the peak area is 1.14 and for retention factor, it is nil. This indicates the system suitability and adequate reproducibility of the equipment.

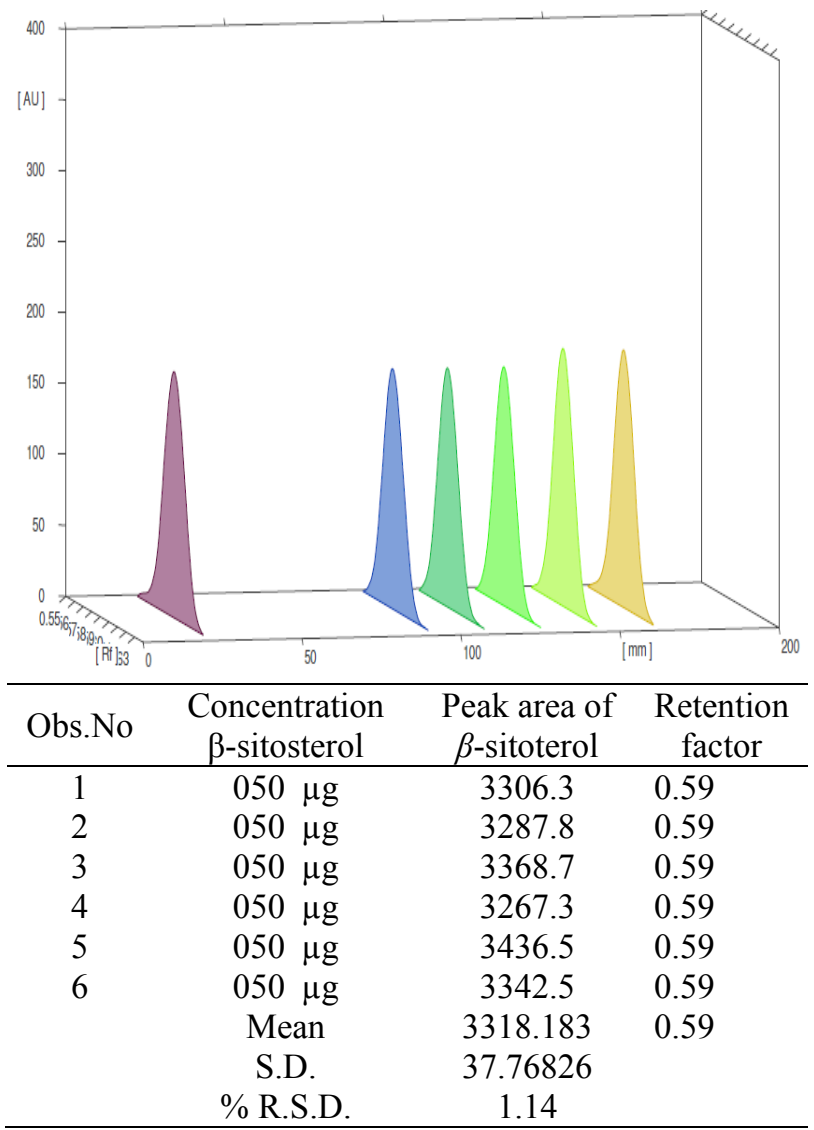

Figure 3. 3D-plot of densitograms of standard $\beta$-sitosterol along with peak area and $\mathrm{R}_{\mathrm{f}}$ value demonstrating system suitability of method

\section{Quantification}

The HPTLC densitogram (Figure 4) and HPTLC profile (Plate No.1) were obtained using standard HPTLC procedure. The identity of the band of $\beta$-sitosterol in leaf extract was confirmed by comparing $\mathrm{R}_{\mathrm{f}}$ value of leaf extracts with that of standard solutions (Figure 5 and Figure 6). Chromatogram of standard $\beta$-sitosterol solution with volume ranging from $4 \mu \mathrm{L}$ to $2 \mu \mathrm{L}$ yielded better results and hence were used for the analysis. Similarly 3 readings of standard sample solution were used for the purpose of quantification as per the guidelines. 


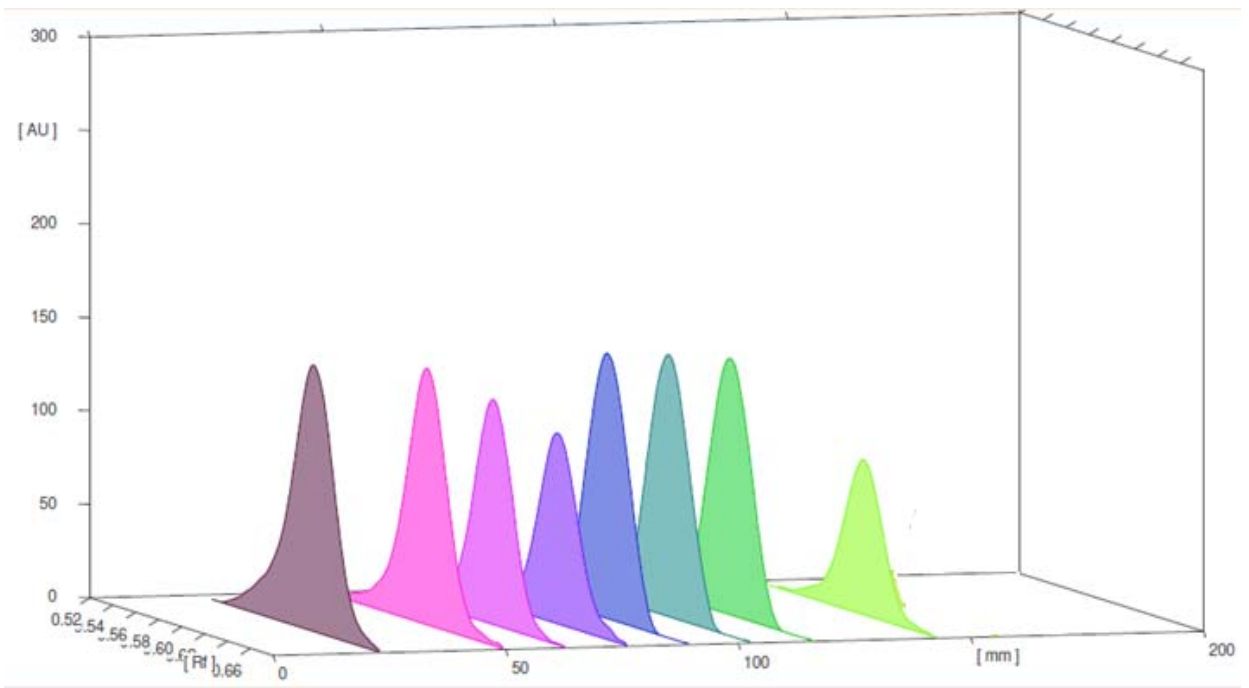

Figure 4. 3D- plot of densitograms of standard $\beta$-sitosterol and leaf extract of Achyranthes aspera Linn.

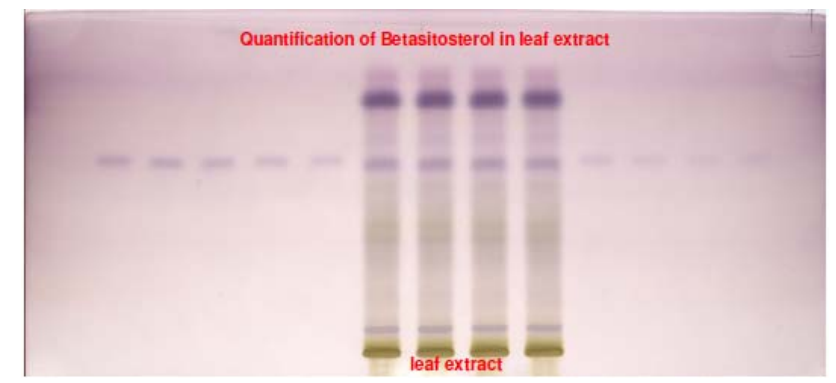

Plate 1. HPTLC profile of Quantification of $\beta$-sitosterol in leaf extract of Achyranthes aspera Linn.

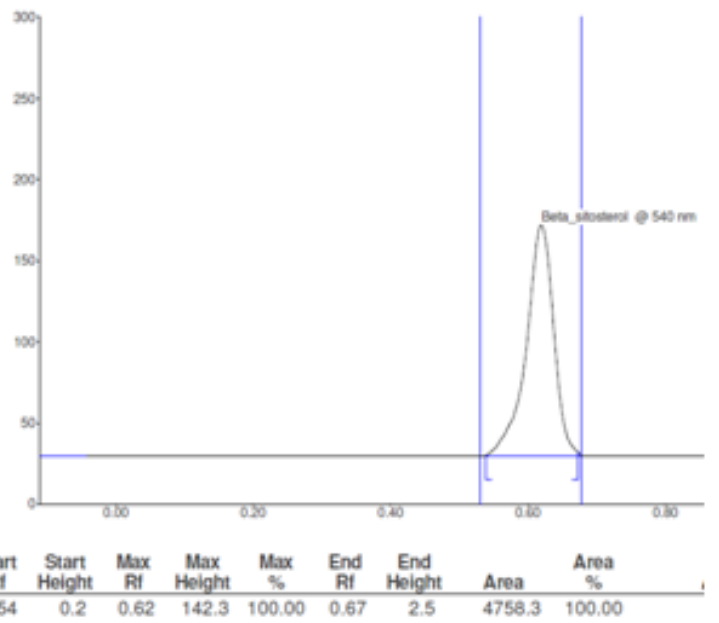

Figure 5. Densitogram of $\beta$-sitosterol with applied vol. $4 \mu \mathrm{L}$ 


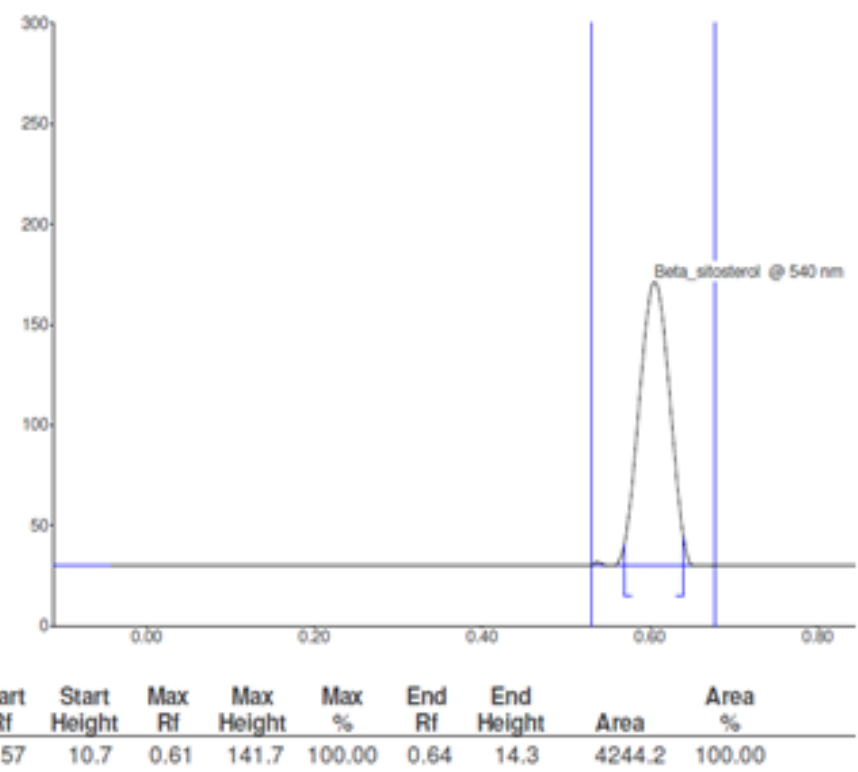

Figure 6. Densitogram of leaf extract of Achyranthes aspera Linn. with applied vol. $10 \mu \mathrm{L}$

Graph of peak area and concentration of $\beta$-sitosterol in leaf extract of Achyranthes aspera Linn. When plotted, shows linear relationship (Figure 7). Using the regression equation of the linear regression graph, the amount of $\beta$-sitosterol in standard solution applied on plate is calculated (Table 4). Similarly, the amount of $\beta$-sitosterol per $10.0 \mu \mathrm{L}$ leaf extract was calculated and the results are given in the Table 5. The concentration of $\beta$-sitosterol in Leaf of the plant is found to be $0.699 \mathrm{ng} / \mu \mathrm{g}$. Distributions with a coefficient of variation $(\% \mathrm{CV})$ in the above results obtained is less than 1 indicating low-variance and thus it can be claimed that the results are fairly reliable.

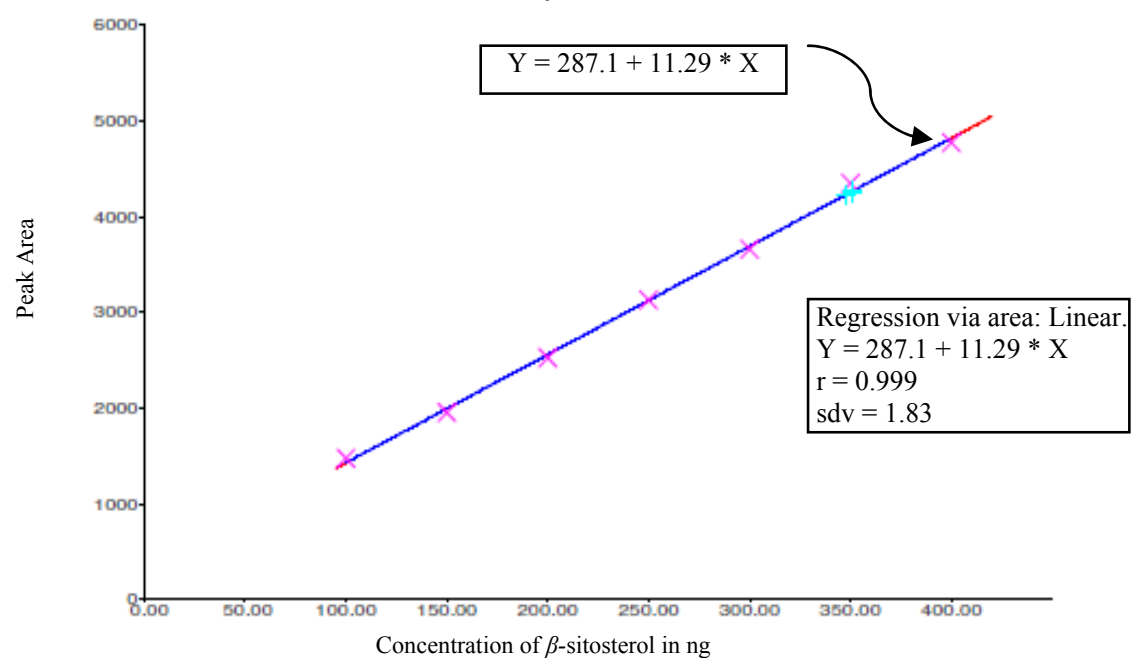

Figure 7. Graph of peak area and concentration of $\beta$-sitosterol and Leaf extract of Achyranthes aspera Linn. 
Table 4. The $\mathrm{R}_{\mathrm{f}}$ values and peak areas corresponding to the serial dilutions of standard compound- $\beta$-sitosterol and fixed amount of leaf extract of Achyranthes aspera Linn.

\begin{tabular}{clllll}
\hline S. No & Appl. Sample & Appl. Vol. & Amount Per spot & $\mathrm{R}_{\mathrm{f}}$ & Peak Area \\
\hline 1 & $\beta$-sitosterol & $4.0 \mu \mathrm{L}$ & $0.4 \mu \mathrm{g}$ & 0.62 & 4758.27 \\
2 & $\beta$-sitosterol & $3.5 \mu \mathrm{L}$ & $0.35 \mu \mathrm{g}$ & 0.61 & 4330.82 \\
3 & $\beta$-sitosterol & $3.0 \mu \mathrm{L}$ & $0.3 \mu \mathrm{g}$ & 0.62 & 3644.61 \\
4 & $\beta$-sitosterol & $2.5 \mu \mathrm{L}$ & $0.25 \mu \mathrm{g}$ & 0.62 & 3116.70 \\
5 & $\beta$-sitosterol & $2.0 \mu \mathrm{L}$ & $0.2 \mu \mathrm{g}$ & 0.62 & 2512.13 \\
6 & Leaf extract & $10.0 \mu \mathrm{L}$ & $500 \mu \mathrm{g}$ & 0.61 & 4244.16 \\
7 & Leaf extract & $10.0 \mu \mathrm{L}$ & $500 \mu \mathrm{g}$ & 0.61 & 4250.57 \\
8 & Leaf extract & $10.0 \mu \mathrm{L}$ & $500 \mu \mathrm{g}$ & 0.61 & 4214.85 \\
\hline
\end{tabular}

Table 5 The amount of $\beta$-sitosterol per $10.0 \mu \mathrm{L}$ of different leaf extracts of Achyranthes aspera Linn.

\begin{tabular}{ccccccc}
\hline $\begin{array}{c}\text { S. } \\
\text { No. }\end{array}$ & Appl. Sample & Appl. Vol. & $\begin{array}{c}\text { Amount } \\
\text { Per spot }\end{array}$ & $\mathrm{R}_{\mathrm{f}}$ & Peak Area & $\begin{array}{c}\text { Amount } \\
\text { of } \beta \text {-sitosterol Per spot }\end{array}$ \\
\hline 1 & Leaf extract & $10.0 \mu \mathrm{L}$ & $500 \mu \mathrm{g}$ & 0.61 & 4244.16 & 350.49 \\
2 & Leaf extract & $10.0 \mu \mathrm{L}$ & $500 \mu \mathrm{g}$ & 0.61 & 4250.57 & 351.11 \\
3 & Leaf extract & $10.0 \mu \mathrm{L}$ & $500 \mu \mathrm{g}$ & 0.61 & 4214.85 & 347.94 \\
& \multicolumn{3}{c}{ Mean } & & & 349.85 \\
& \multicolumn{3}{c}{ SD } & & 1.68 \\
& & & 0.480 \\
\hline
\end{tabular}

\section{Conclusion}

A new validated HPTLC method has been developed and used for the quantification of $\beta$ sitosterol from the methanolic extract of leaves of Achyranthes aspera Linn. The developed HPTLC technique can be used for the routine quality control analysis and quantitative determination of $\beta$-sitosterol from Achyranthes aspera Linn. The $\beta$-sitosterol was found to be linear in the range of $0.20 \mu \mathrm{g} / \mu \mathrm{L}-0.40 \mu \mathrm{g} / \mu \mathrm{L}$. Considering the wide therapeutic applications of $\beta$-sitosterol an alternative quantification technique of this marker constituent was generated to ensure identity and quality of the selected plant. This is a sensitive, specific and reproducible HPTLC method for the quantification of $\beta$-sitosterol from leaves of Achyranthes aspera Linn.

\section{References}

1. Anonymous. The Wealth of India-Raw Materials, Council of Scientific \& Industrial Research, New Delhi, 2005, 55-57.

2. Jain J B, Kumane S C and Bhattacharya S, Indian J Traditional Knowledge, 2006, 5(2), 237-242.

3. Zafar R, Medicinal Plants of India. CBS publishers \& distributors, 2006, 1-15.

4. Paul D, De D, Ali KM, Chatterjee K, Nandi D K, Ghosh D, Contraception, 2010, 81(4), 355-361

5. Sutar N G, Sutar U N, Sharma Y P, Shaikh I K and Kshirsagar S S, Biosci Biotechnol Res Asia, 2008, 5(2), 841-844.

6. Neogi N C, Garg R D and Rathor R S, Indian J Pharmacy, 1970, 32(2), 43-46.

7. Girach R D and Khan A S A, Int J Pharmacogn., 1992, 30, 113-115. 
8. Han S T and Un C C, Vet Hum Toxicol., 2003; 45(4), 212-223.

9. Chungsamarnyart N, Jiyajinda S and Jangsawan W, Kasetsert J., 1991, 25, 80-89.

10. Valsaraj R, Pushpangadan P, Smitt U W, Andersen A and Nyman U, $J$ Ethnopharmacol., 1997, 58(2), 75-83; DOI:10.1016/S0378-8741(97)00085-8

11. Ghani A, Medicinal Plant of Bangladesh with Chemical Constituents and Uses, $2^{\text {nd }}$ Ed., Asiatic Society of Bangladesh, Dhaka, 2003, 71-72.

12. Tahiliani P and Kar A, J Ethanopharmacol., 2000, 71(3), 527-532; DOI:10.1016/S03788741(00)00170-7

13. Elumalaii E K, Chandrasekaran N, Thirumalaii T, Sivakumari C and Viviyan Therasa S, Int J PharmTech Res., 2009, 1(4), 1576-1579.

14. Shailajan S, Naresh C, Sane R T and Sasikumar M, Indian J Exp Biol., 2005, 43, 68-75.

15. Ahmed S, Rahman A, Mathur M, Athar M and Sultana S, Food Chem Toxicol., 2001, 39(1), 19-28; DOI:10.1016/S0278-6915(00)00103-4

16. Karl H P, South Afr J Sci., 1997, 93, 263-268.

17. Gupta M B, Nath R, Srivastava N, Kishor K and Bhargava K P, Planta Medica, 1980, 39, 157-163.

18. Bouic P J D, Etsebeth S, Liebenberg R W, Albrecht C F, Pegel K and Van Jaarsveld $\mathrm{P}$ P, Int J Immunopharmacology, 1996, 18(12), 693-700; DOI:10.1016/S01920561(97)85551-8

19. International Conference on Harmonization ( $\mathrm{ICH}$ ) of Technical Requirements for Registration of Pharmaceuticals for Human use, Harmonised Triplicate Guideline on Validation of Analytical Procedures: Methodology, Recommended for Adoption at Step 4 of the ICH process on November 1996 by the ICH Steering Committee, IFPMA, Geneva.

20. Center for Drug Evaluation and Research (CDER) Reviewer Guidance, Validation of Chromatographic Methods, November 1994. 